\title{
Infrared spectroscopic investigation of erythrocyte membrane-smoke interactions due to chronic cigarette smoking
}

\author{
Mahmoud S. Sherif, Ali A. Mervat and Aly M. Eman \\ Biophysics and Laser Science Unit, Research Institute of Ophthalmology, 2 Al-Ahram Street, Giza, Egypt
}

\begin{abstract}
Cigarette smoking is a serious health problem throughout the world, with a complicated and not totally clear bio-effect. In this study, erythrocytes were obtained from healthy male volunteers aged $22 \pm 2$ years and, the possible effects of three cigarette smoking rates namely 10,15 and 20 cigarette/day on erythrocytes membrane characteristics were examined by Fourier transform infrared spectroscopy (FTIR). The results of this study indicate many smoking-dependent variations on erythrocytes membrane without an obvious dose-response relationship. There was disruption in the acyl chain packing; changes in membrane order and phases as well as membrane proteins becoming more folded. These physico-chemical changes should have an impact on the function of erythrocytes and may explain the complex interaction of cigarette smoke mainstream with erythrocyte membrane and to some extent clarify the pathological processes associated with cigarette smoking.
\end{abstract}

Key words: Cigarette smoke - Erythrocyte membrane - FTIR - Protein - Lipid

\section{Introduction}

Cigarette smoking - a worldwide social habit - is associated with well documented numerous health hazards that include lung cancer, stroke, respiratory, cardiovascular diseases and osteoporosis (Mello 2010). These health risks result from the entrance of the mainstream smoke into the blood which leads to alterations in the blood constituents, plasma, erythrocytes, platelets and leukocytes (Freeman et al. 2005), and have been attributed to the abundance of reactive oxygen species and reactive nitrogen species (Barua et al. 2003). More smoking health hazards that should be addressed are the ocular ones aggravated by cigarette smoke which include dry eye (Arffa 1991), conjunctival irritation, age-related macular degeneration, cataract, ocular inflammation and change in tear characteristics (Satici et al. 2003; Sprague et al. 2006; Thorne et al. 2008; Lin et al. 2010; Roesel et al. 2011). In addition, the retina is known to have the highest rate of oxygen consumption of any organ in the body (Kewal 2011). Therefore any alterations in the structure and/or function of the erythrocyte membranes should have an impact on retinal function.

Correspondence to: Sherif Siddick Mamhmoud, Biophysics and Laser Science Unit, Research Institute of Ophthalmology, P.O. Box 90, 2 Al-Ahram Street, Giza, Egypt

E-mail: sheri_sm@yahoo.com
Padmavathi et al. (2010) found that chronic cigarette smoking alters the content of individual phospholipids of erythrocytes membrane that was associated with increased membrane lipid peroxidation. The erythrocytes membranecigarette smoke interactions appear to be more complex and the exact mechanism that enhance these effects remain uncertain. Therefore, the present study is aimed to understand the effect of chronic cigarette smoke exposure on the erythrocyte membrane structural and conformational characteristics that were studied by Fourier transform infrared spectroscopy (FTIR) while taking into account the smoking rate (number of cigarette smoked/day) and the dose-response relationship if any.

\section{Participants and Methods}

Subjects

Four groups of healthy male subjects were involved in this study, where each group composed of 25 age-matched subjects ( $22 \pm 2$ years). Three groups were cigarette smokers for $3 \pm 1$ year but differ in the daily smoking rate as 10,15 and 20 cigarette/day (cig/day), and the last group served as the control one. All study subjects had normal renal and hepatic functions with no evidence of any acute infection 
or active inflammatory process. None of the subjects had hypertension, were taking any medications or receiving vitamin supplementation. There was no significant obesity observed between all subjects $(\mathrm{BMI}=22.4 \pm 3.6)$, as well as cholesterol $(155 \pm 15 \mathrm{mg} / \mathrm{dl})$ and triglycerides $(125 \pm 8 \mathrm{mg} / \mathrm{dl})$, with normal fasting blood glycemic level $(90 \pm 5 \mathrm{mg} / \mathrm{dl})$. All subjects signed an informed consent with tenets of the Declaration of Helsinki.

\section{Preparation of erythrocyte membranes}

Blood was obtained by veinpuncture, collected into heparinized syringes and immediately centrifuged at $500 \times g$ at $4^{\circ} \mathrm{C}$ for $10 \mathrm{~min}$. The plasma and buffy coat were discarded, and erythrocytes were re-suspended and washed three times in physiological saline $(0.9 \% \mathrm{NaCl})$. Erythrocyte membranes were prepared as previously mentioned by Sprague et al. 2006. The washed erythrocytes were added to $200 \mathrm{ml}$ of hypotonic buffer $(5 \mathrm{mmol} / \mathrm{l}$ Tris- $\mathrm{HCl}, 2 \mathrm{mmol} / \mathrm{EDTA}, \mathrm{pH}$ 7.4) and stirred vigorously for $20 \mathrm{~min}$. The mixture was centrifuged at $23,000 \times g$ for $15 \mathrm{~min}$, and the supernatant was discarded. After repeating the last step one more time, membranes were pooled, resuspended in buffer and centrifuged. Finally, after discarding the supernatant, membranes were freeze-dried and kept under $\mathrm{N}_{2}$ gas atmosphere for further analysis.

\section{Fourier transform infrared spectroscopy}

Erythrocytes membrane was mixed with finely ground powder $\mathrm{KBr}$ to prepare the $\mathrm{KBr}$-disks that were used in analysis. This mixture was placed in a special holder pro-

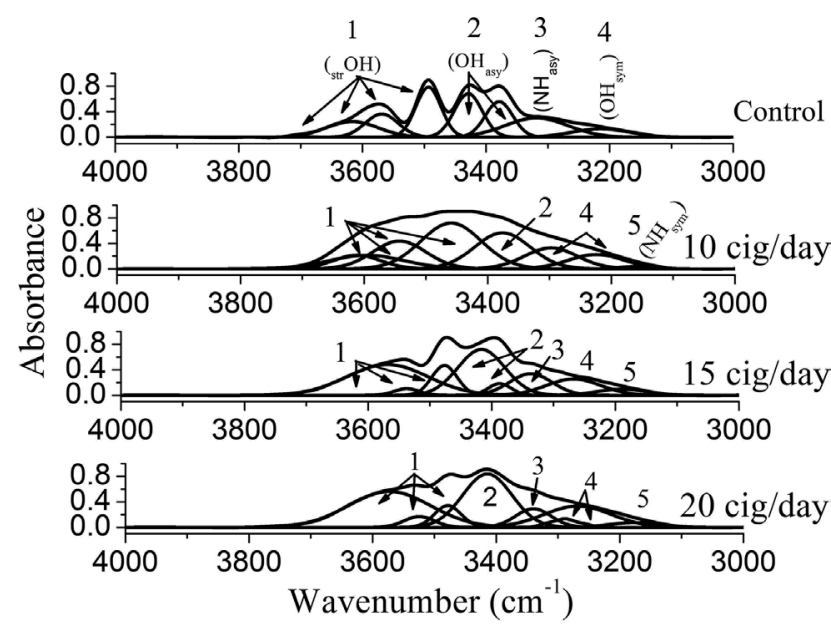

Figure 1. Erythrocytes membrane NH-OH region $\left(4000-3000 \mathrm{~cm}^{-1}\right)$ of the control group and cigarette smoking ones, showing the underlying bands that detected upon using curve fitting analysis. The numbers above the peaks to facilitate their assignment. vided by the manufacturer and pressed under vacuum at 3 tons (13.8 MPa) for 2 min to produce IR-KBr disks (Sherif 2010). FTIR measurements were carried out using NicoletiS5 infrared spectrometer (ThermoFisher Scientific Inc, Madison, USA) with effective resolution of $2 \mathrm{~cm}^{-1}$. Each spectrum was derived from 100 sample interferograms. The spectrometer was operated under a continuous dry $\mathrm{N}_{2}$ gas purge to remove interference from atmospheric $\mathrm{CO}_{2}$ and $\mathrm{H}_{2} \mathrm{O}$ vapor. The spectra were baseline corrected and then smoothed with Savitsky-Golay to remove the noise before Fourier transformation. Three spectra from each sample were obtained and averaged using OriginPro 7.5 software to obtain the final average group spectrum that was normalized and analyzed for the following spectral regions: $4000-3000 \mathrm{~cm}^{-1}$ (NH-OH region), $3000-2800 \mathrm{~cm}^{-1}(\mathrm{CH}$ stretching region), $1800-1600 \mathrm{~cm}^{-1}$ (amide I region) and $1600-900 \mathrm{~cm}^{-1}$ (fingerprint region), and then subjected to curve enhancement analysis using a combination of Fourier deconvolution and non-linear curve fitting. The second derivative of the group spectrum was employed to confirm the number of the estimated peaks.

\section{Statistical analysis}

Results were calculated and expressed as mean \pm standard deviation (SD). Comparison between multiple groups was performed using analysis of variance (ANOVA); commercially available statistical software package (SPSS-11 for Windows) was used where the significance level was set at $p<0.05$. All spectral analyses were performed with OriginPro 7.5 software package (Origin Lab Corporation, Northampton, MA, USA).

\section{Results}

The erythrocytes infrared spectra were analyzed according to the following described regions.

\section{$\mathrm{NH}-\mathrm{OH}$ region}

In Figure 1, the contour of the control erythrocytes membrane indicates the presence of several absorption bands that were resolved into 8 structural components using the curve enhancement procedure as given in Table 1. In the same context, the contour of smokers' erythrocytes membrane was also resolved into 8 structural peaks that differed in band position, band area and bandwidth as well as their assignment Table 1 . The stretching $\mathrm{OH}\left({ }_{s t r} \mathrm{OH}\right)$ compositional bands were reduced from four components in the control and $10 \mathrm{cig} /$ day groups to three structural components as the number of smoked cigarettes increased to $15 / 20$ daily. 
The two structural components of the asymmetric $\mathrm{OH}$ $\left({ }_{\text {asym }} \mathrm{OH}\right)$ bond were reduced to one component in two groups only; $10 \mathrm{cig} / \mathrm{day}$ and $20 \mathrm{cig} /$ day that were characterized by significantly increased bandwidth and band area. At a smoking rate of $15 \mathrm{cig} /$ day, the two detected structural component show paradox characteristics; where the higher frequency band has an increased band area and bandwidth while the lower frequency one has decreased band area and bandwidth. On the other hand, symmetric $\mathrm{OH}\left({ }_{\mathrm{sym}} \mathrm{OH}\right)$ band showed a different behavior; increased vibrational frequency and band area that were associated to different smoking rates, this is in addition to its splitting into 2 structural components at a daily smoking rate of 10 and 20 cigarette compared to control one as shown in Table 1.

For all smoking groups, the symmetric $\mathrm{NH}\left({ }_{\text {sym }} \mathrm{NH}\right)$ stretching vibrational mode was detected. Comparing the three smoking groups, it is noticed that this vibrational mode was characterized by increased vibrational frequency, band area as well as bandwidth as the number of cigarette smoked increased from 10 to $15 / 20$ daily while, the asymmetric vibrational mode of the $\mathrm{NH}$ band $(\operatorname{asym} \mathrm{NH})$ was restricted at $10 \mathrm{cig} /$ day smoking group, then detected again as the smoking rate increased to $15 / 20$ daily and is characterized by increased vibrational frequency and bandwidth as well. The band area was reduced at $20 \mathrm{cig} /$ day smoking group.

\section{CH stretching region}

The $\mathrm{CH}$ stretching pattern of the control erythrocytes indicated the presence of four absorption bands that were centered at $2962 \pm 3,2920 \pm 2,2870 \pm 2$ and $2846 \pm 3 \mathrm{~cm}^{-1}$ and assigned to asymmetric $\mathrm{CH}_{3}\left({ }_{\text {asym }} \mathrm{CH}_{3}\right)$, asymmetric $\mathrm{CH}_{2}\left({ }_{\text {asym }} \mathrm{CH}_{2}\right)$, symmetric $\mathrm{CH}_{3}\left({ }_{\text {sym }} \mathrm{CH}_{3}\right)$ and symmetric $\mathrm{CH}_{2}\left({ }_{\text {sym }} \mathrm{CH}_{2}\right)$ respectively (Figure 2). This pattern was changed in all smoking subjects. The number of absorption bands was decreased at 10 and $15 \mathrm{cig} /$ day smoking groups with restricted ${ }_{\text {sym }} \mathrm{CH}_{2}$ vibrational mode. Subjects with smoking rate of $20 \mathrm{cig} /$ day showed a different $\mathrm{CH}$ vibrational pattern; in addition to the restricted ${ }_{\text {sym }} \mathrm{CH}_{2}$ mode, there is an additional stretching mode of vibration that was detected at $2904 \pm 2 \mathrm{~cm}^{-1}$ and attributed to aliphatic $\mathrm{CH}\left(\mathrm{CH}_{\text {aliph }}\right)$. There is no change in band position or bandwidth of smoking subjects' asym $\mathrm{CH}_{3}$ or ${ }_{\text {sym }} \mathrm{CH}_{3}$ while, the band position of smoking asym $\mathrm{CH}_{2}$ was found to be increased relative to the control pattern as given in Table 2. This table also shows undetectable changes in band area of asym $\mathrm{CH}_{3}, \mathrm{asym}_{2} \mathrm{CH}_{2}$ and ${ }_{s y m} \mathrm{CH}_{3}$ bands relative to their corresponding control ones.

\section{Amide I region}

Analysis of amide I band by using the curve enhancement procedure (Figure 3) resolved the control band into three

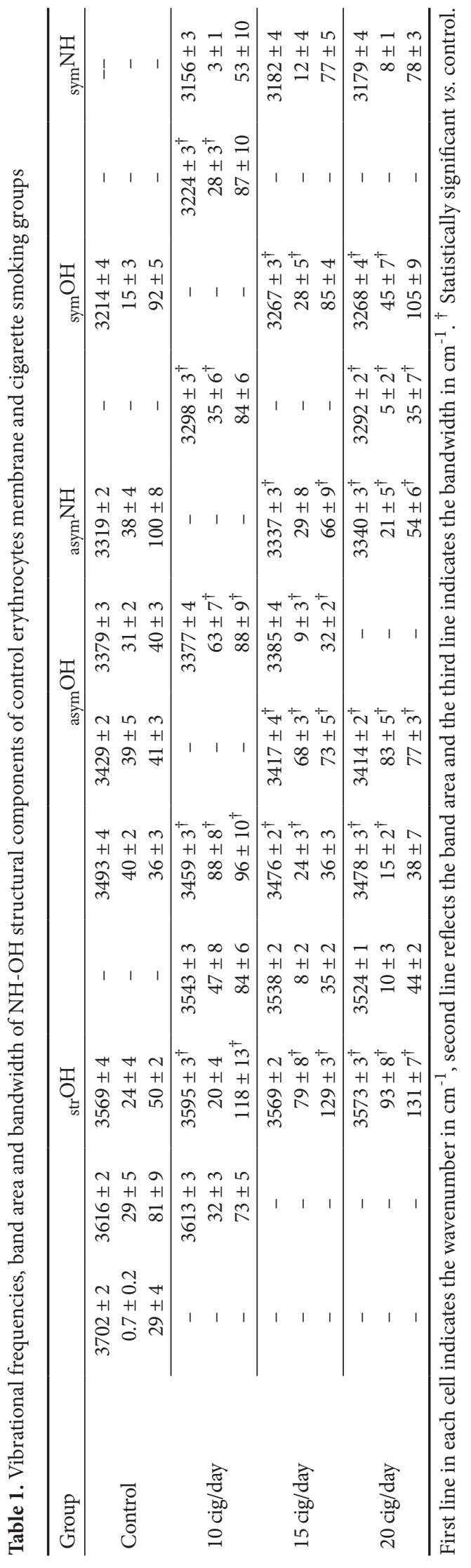




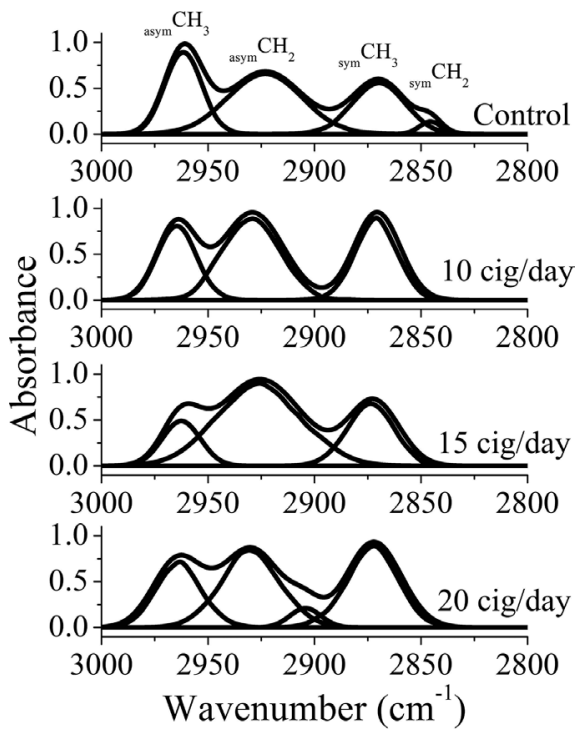

Figure 2. Stretching $\mathrm{CH}$ region $\left(3000-2800 \mathrm{~cm}^{-1}\right)$ of control and cigarette smoking erythrocytes membrane.

structural components that are centered at $1688 \pm 3,1655 \pm 2$ and $1623 \pm 2 \mathrm{~cm}^{-1}$ and can be attributed to $\beta$-turn structure, $\alpha$-helix and $\beta$-sheet, respectively (Lin et al. 1998). Due to cigarette smoking, the contour of amide I can be resolved into five structural components with additional structural components that were centered on $1663 \pm 3$ and $1612 \pm 2 \mathrm{~cm}^{-1}$ and can be assigned to turns and antiparallel $\beta$-sheet. The significance of these results is presented in Table 3 , which shows the area percentage of each structural component relative to the total band area. Alpha-helix content is sig-

Table 2. Erythrocytes membrane characteristics of $\mathrm{CH}$ stretching region of control and cigarette smoking groups

\begin{tabular}{lrrcrc}
\hline Group & asym $\mathrm{CH}_{3}$ & asym $\mathrm{CH}_{2}$ & $\mathrm{CH}_{\text {aliph }}$ & sym $\mathrm{CH}_{3}$ & sym $\mathrm{CH}_{2}$ \\
\hline \multirow{5}{*}{ Control } & $2962 \pm 3$ & $2920 \pm 2$ & - & $2870 \pm 2$ & $2846 \pm 3$ \\
& $20 \pm 2$ & $31 \pm 4$ & - & $23 \pm 3$ & $1.8 \pm 0.2$ \\
& $17 \pm 3$ & $35 \pm 5$ & - & $25 \pm 3$ & $10 \pm 2$ \\
\hline \multirow{4}{*}{$10 \mathrm{cig} /$ day } & $2965 \pm 2$ & $2929 \pm 3$ & - & $2871 \pm 2$ & - \\
& $20 \pm 2$ & $35 \pm 5$ & - & $26 \pm 3$ & - \\
& $18 \pm 4$ & $29 \pm 4$ & - & $22 \pm 4$ & - \\
\hline \multirow{5}{*}{$15 \mathrm{cig} /$ day } & $2963 \pm 3$ & $2926 \pm 3^{\dagger}$ & - & $2872 \pm 2$ & - \\
& $18 \pm 5$ & $42 \pm 9$ & - & $21 \pm 4$ & - \\
& $18 \pm 4$ & $39 \pm 4$ & - & $24 \pm 3$ & - \\
\hline \multirow{5}{*}{$20 \mathrm{cig} /$ day } & $2964 \pm 2$ & $2930 \pm 3^{\dagger}$ & $2904 \pm 2$ & $2872 \pm 2$ & - \\
& $21 \pm 4$ & $31 \pm 3$ & $4 \pm 1$ & $30 \pm 6$ & - \\
& $23 \pm 5$ & $28 \pm 5$ & $14 \pm 3$ & $26 \pm 3$ & - \\
\hline
\end{tabular}

First line in each cell represents the frequency in $\mathrm{cm}^{-1}$, second line indicates the band area and third line reflects the bandwidth in $\mathrm{cm}^{-1} .{ }^{\dagger}$ statistically significant $v s$. control.
Table 3. Protein secondary structure components expressed as the area percentage of each structural component relative to the total band area

\begin{tabular}{lcccc}
\hline Group & $\alpha$-helix & $\beta$-turns & $\beta$-sheet & Turns \\
\hline Control & $80 \pm 4.8$ & $10.4 \pm 1.1$ & $9.6 \pm 2.8$ & - \\
$10 \mathrm{cig} /$ day & $54.1 \pm 3.1^{\dagger}$ & $14.8 \pm 1.7^{\dagger}$ & $17.3 \pm 1.6^{\dagger}$ & $13.8 \pm 3.3$ \\
$15 \mathrm{cig} /$ day & $32.2 \pm 2.4^{\dagger}$ & $23.7 \pm 2.7^{\dagger}$ & $19.2 \pm 2.5^{\dagger}$ & $24.9 \pm 2.6$ \\
$20 \mathrm{cig} /$ day & $37.9 \pm 2.3^{\dagger}$ & $20.9 \pm 1.8^{\dagger}$ & $20.8 \pm 1.3^{\dagger}$ & $20.4 \pm 4.2$ \\
\hline
\end{tabular}

$\dagger^{\dagger}$ statistically significant $v$ s. control.

nificantly decreased in all smoking groups concomitant with a significant increase in $\beta$-turn and $\beta$-sheet structures. The interesting finding is the detection of Turns-structure that was associated to all smoking rates (Rose et al. 1985).

\section{Fingerprint region}

The other frequency range under consideration is 1600$900 \mathrm{~cm}^{-1}$, which is shown in Figure 4. There is broadening in the contour of smoking groups with reduction in the absorption intensities; concomitant to reduced number of the estimated peaks. The control pattern shows seven absorption bands with eleven estimated structural peaks as given in Table 4 . No change in the band characteristics (frequency, bandwidth or band area) of amide II while, reduced band area of asymmetric COOC (asymCOOC) band was found. The splitting noticed in both scissoring $\mathrm{CH}_{2}\left({ }_{\text {sciss }} \mathrm{CH}_{2}\right)$ and symmetric $\mathrm{PO}_{2}\left({ }_{\text {sym }} \mathrm{PO}_{2}\right)$ bands of control group was restricted in all smoking ones. Another

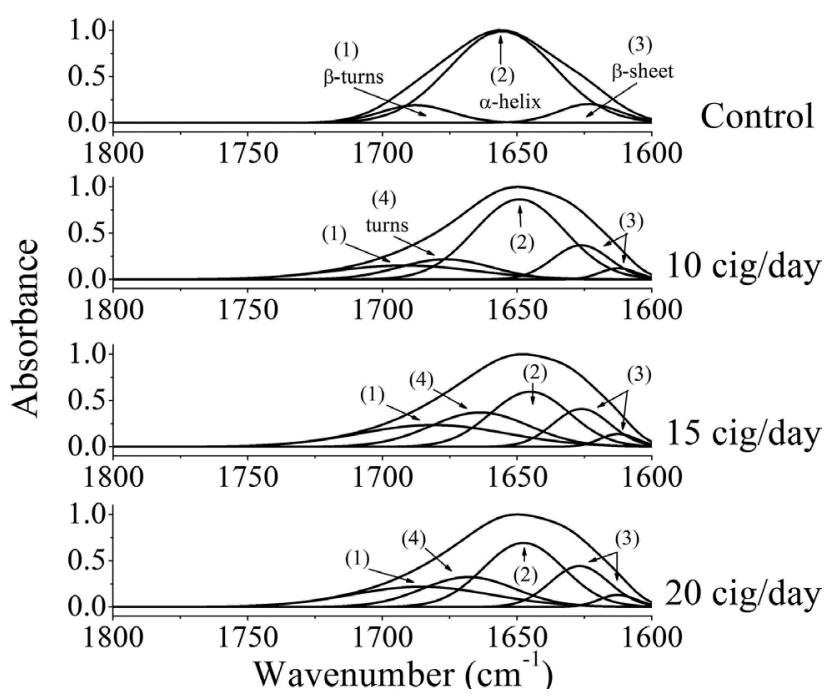

Figure 3. Analysis of Amide I band showing the mean peak and the underlying structural components. The numbers above the peaks is to facilitate their assignment. 
common feature noticed in these two bands is the increased bandwidth that was associated to different smoking rates. The band position of ${ }_{\text {sym }} \mathrm{PO}_{2}$ was sensitive to all smoking rates (decreased), while that of ${ }_{\text {sciss }} \mathrm{CH}_{2}$ was increased in 10 and $15 \mathrm{cig} /$ day groups only. The symmetric $\mathrm{COO}$ ( $\left.{ }_{\text {sym }} \mathrm{COO}\right)$ higher frequency estimated component was characterized by decreased vibrational frequency in all smoking subjects, and this is contrary to the lower frequency one where its vibrational frequency was increased while, both of them were associated with reduced band area and vibrational motion (bandwidth). Reduced band position and band area was detected for the asymmetric $\mathrm{PO}_{2}\left({ }_{\text {asym }} \mathrm{PO}_{2}\right)$ band without any change in its vibrational motion. Also, no splitting was found in the rocking $\mathrm{CH}_{3}\left({ }_{\text {rock }} \mathrm{CH}_{3}\right)$ band in all smoking groups with fluctuations in its vibrational frequency that was associated with increasing vibrational motion. In the same context, increased band area was also detected for the higher frequency band relative to its corresponding control band.

\section{Discussion}

Cigarette mainstream is a complex and heterogeneous mixture that contains volatile chemicals (e.g. formaldehyde), particles (e.g. nicotine) and gases (e.g. carbon monoxide). Moreover, a puff of cigarette smoke can contain about 300 million to 3.5 billion particles (Satici et al. 2003; Galor and Lee 2011). It also contains more than $10^{14}$ low-molecular carbon and oxygen centered radicals per puff with almost $500 \mathrm{ppm}$ nitric oxide and other reactive nitrogen oxides (Pryor et al. 1993).

The obtained results from $\mathrm{NH}-\mathrm{OH}$ region showed several fluctuated changes associated to different smoking rates, and only two structural components - namely ${ }_{\text {str }} \mathrm{OH}$ that detected at an average vibrational frequency of $3535 \pm 10 \mathrm{~cm}^{-1}$ and ${ }_{\text {sym }} \mathrm{NH}$ one - can be directly related to cigarette smoking, meaning that can be used to monitor/ probe the impact of cigarette smoking on the erythrocytes membrane. This region also indicates that the detected sym $\mathrm{NH}$ mode should had another impact on the function of erythrocytes membranes since it is an indicator that the membrane become more ordered as previously reported by Schultz et al. (1998) that symmetric stretching vibrations are functioning as a marker for membrane order. In spectroscopy, the area under the peak is used as an estimate of the concentration of the compound. Regarding this issue, the increased membrane order is also evident by the increased concentration of all structural components of ${ }_{\text {sym }} \mathrm{OH}$ band and to clarify this last finding, the ratio of total band areas of ${ }_{\text {sym }} \mathrm{OH} /$ asym $\mathrm{OH}$ in control erythrocytes was 0.2 while it increased as the smoking rate increased to 15 and 20 cigarette/day to be 0.4 and 0.6 respectively. In the same context, the relative-total concentration of the individual structural

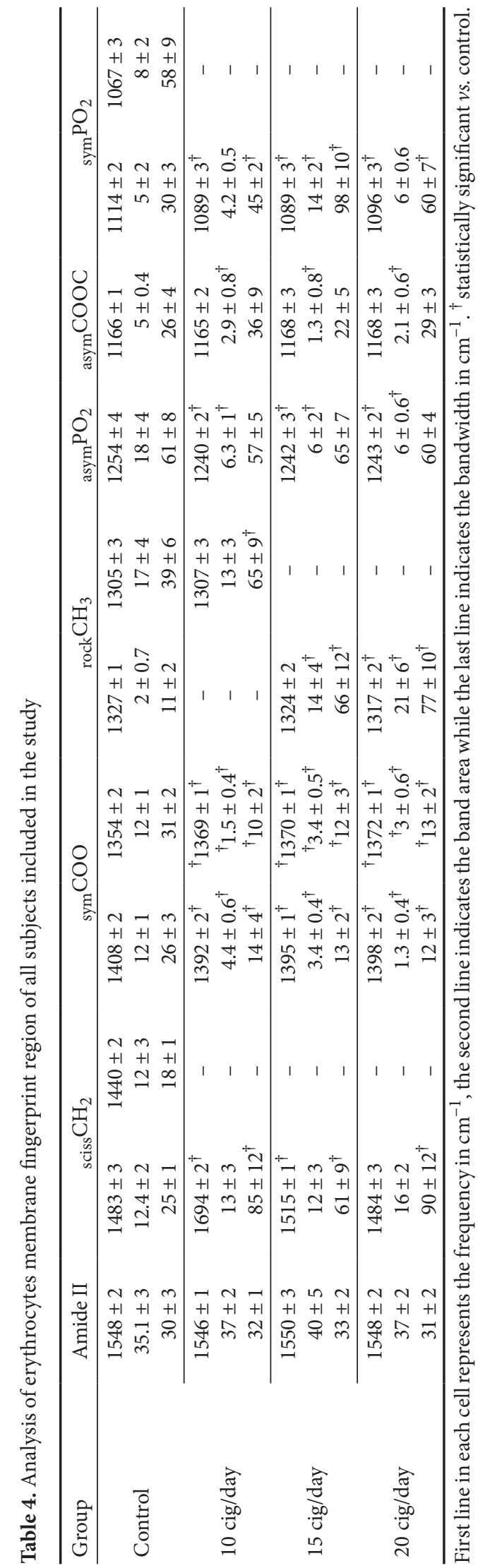




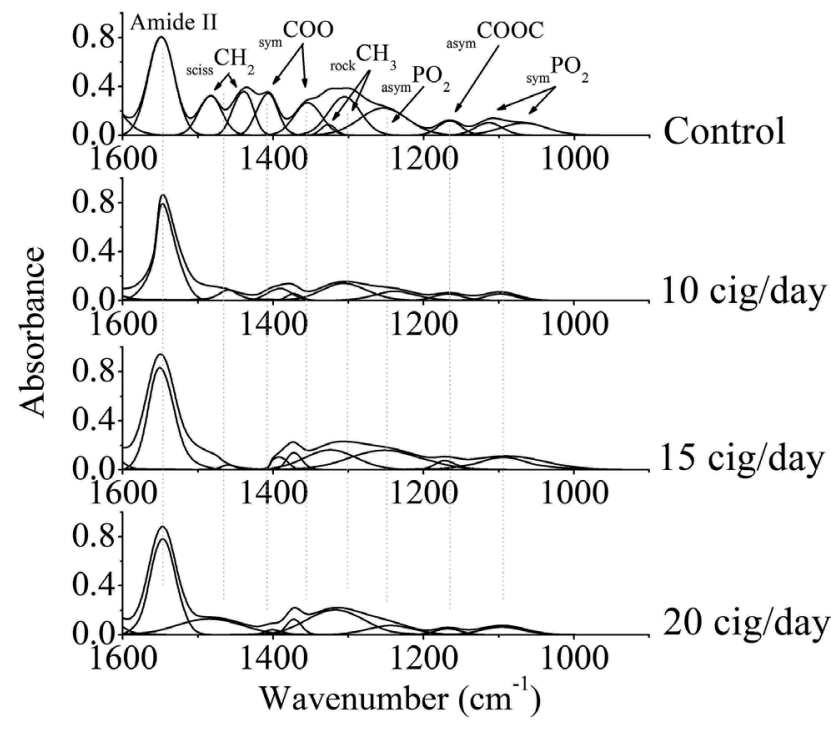

Figure 4. FTIR spectra of fingerprint region of different erythrocytes membranes involved in this study.

components of ${ }_{\text {str }} \mathrm{OH}$ bands was also found to be increased from $93 \pm 4$ in the control erythrocytes and reaches $187 \pm 5$, $111 \pm 2$ and $118 \pm 2$ that corresponds to smoking rates of 10,15 and 20 cigarette/day. The $\mathrm{OH}$ bond can be found in many membrane constituents and one of these possibilities is cholesterol, which may support this finding about increased erythrocytes membrane order.

On the other hand, the $\mathrm{CH}$ region was greatly affected by all smoking rates involved in this study and, in particular symmetric and asymmetric $\mathrm{CH}_{2}$ bands which again give the impetus about the possibility of using these two bands to probe cigarette smoking-induced changes. This vibrational region is used generally to characterize the lipid molecules within the cell membrane. As shown in Figure 2 and Table 2, there are changes in the molecular environment of the asym $\mathrm{CH}_{2}$ as reflected by increased band position. The disappeared ${ }_{\text {sym }} \mathrm{CH}_{2}$ mode of vibration was previously reported by Szalontai et al. (2003) and Sherif (2010) and referred to it as a lipid-related phenomenon correlated with changes in protein secondary structure. This vibrational region can also be used to monitor the compositional changes of the erythrocytes membrane by considering the concentration ratio asym $\mathrm{CH}_{3}$ (lipids)/ sym $\mathrm{CH}_{3}$ (protein). For control erythrocyte membrane this ratio was found to be 0.9 , while it decreased for smoking rates of 10 and 20 cigarette/day to 0.8 and 0.7 , respectively; and mimicking the control value for 15 cigarette/ day group. This reveals that erythrocyte membranes, and due to different smoking rates, are suffer from fluctuating lipid/protein ratio and it may be a buffering response for the induced cigarette stress.
Proteins in biological membranes can perturb the lipid environment and, depending on their nature and concentration, influence membrane fluidity (Chapman et al. 1979; Szalontai et al. 2003). The erythrocyte proteins are essential for the linkage connecting the membrane skeleton to the lipid bilayer, which is also essential for membrane stability (Lux et al. 1978). The skeletal protein network appears to play a key role in the maintenance of the membrane's discoid shape and in restriction of the lateral mobility of its molecules (Goodman and Branton 1978; Low et al. 1991). Amide I mode of vibration in the $1800-1600 \mathrm{~cm}^{-1}$ spectral region was used to study the protein secondary structure in infrared spectroscopy since this absorption is mainly associated with $\mathrm{C}=\mathrm{O}$ stretching vibrations and it is suitable as a probe to determine the different secondary structures and polypeptides (Susi et al. 1967; Lux 1979). The obtained results (Figure 3 and Table 3 ) show that the protein secondary structure was affected by all smoking rates. It has been suggested that protein insolubility is functioning in the content of $\beta$-sheet structure: more $\beta$-sheet structure means more insoluble protein and, the formation of $\beta$-sheet can be deduced by firstly increasing the disordered structure of the helical structure, and then, the disordered chains aggregate to form $\beta$-sheet structure (Zagorski and Barrow 1992; Lin et al. 1998). Accordingly, smoking rates of 10, 15 and $20 \mathrm{cig} /$ day strongly affect the solubility of erythrocytes membrane protein and resulted in insoluble protein as indicated by both reduced $\alpha$-helix content and the associated increased $\beta$-sheet content, as well as protein becomes more folded due to increased $\beta$-turns and turns structure. These complex changes in erythrocytes membrane protein secondary structure explain the disappearance of ${ }_{\text {sym }} \mathrm{CH}_{2}$ mode of vibrations as previously mentioned. Maintenance of appropriate membrane lipid composition and fluidity are important for the proper functioning of integral membrane proteins, membrane bound enzymes, receptors and ion channels (Swapna el al. 2006; Reddy et al. 2009).

The complicated effects of smoking are also evident in the fingerprint region. The erythrocytes membrane pattern shown in Figure 4 and analyzed in Table 4, reflect the fact that erythrocytes hydrocarbon chains ( ${ }_{\text {sciss }} \mathrm{CH}_{2}$ and ${ }_{\text {rock }} \mathrm{CH}_{3}$ ) and the phospholipids $\left({ }_{\text {sym }} \mathrm{PO}_{2}\right)$ can be found in two different phases, which greatly affected - by all smoking rates involved in this study - and turned into one phase. Moreover, the ${ }_{\text {sciss }} \mathrm{CH}_{2}$ vibrations are characteristic of the nature of the acyl chain packing (Cameron et al. 1980; Swapna et al. 2006) hence; cigarette smoking has an effective impact on the acyl chain packing within the erythrocytes membrane.

Altogether showed that erythrocytes membrane reacts positively with cigarette smoke mainstream in a complicated manner without any specific trends where all membrane constituents are involved, and there were certain vibrational modes that can be used as a probing marker for cigarette 
smoking aggravated changes. Regardless the number of cigarette smoked/day, it affects the $\mathrm{NH}-\mathrm{OH}$ region of either proteins or phospholipids where each smoking rate has its own effects. Cigarette smoking resulted in increased erythrocytes membrane order which affects the membrane fluidity and accordingly its function. The changes in protein secondary structure, acyl chain packing and the detected compositional changes of the $\mathrm{CH}$ region could influence the discoid shape of the erythrocytes.

Conflict of interest. There are no conflicts of interest related to any of the participants in this research work.

\section{References}

Arffa R. C. (1991): Grayson's Diseases of the Cornea. St Louis, Mosby Year Book

Barua R. S., Ambrose J. A., Srivastava S., DeVoe M. C., EalesReynolds L. J. (2003): Reactive oxygen species are involved in smoking induced dysfunction of nitric oxide biosynthesis and upregulation of endothelial nitric oxide synthase: an in vitro demonstration in human coronary artery endothelial cells. Circulation 107, 2342-2347

https://doi.org/10.1161/01.CIR.0000066691.52789.BE

Cameron D. G., Casal H. L., Mantsch H. H. (1980): Characterization of the pretransition in 1,2-dipalmitoyl-sn-glycero3-phosphocholine by Fourier transform infrared spectroscopy. Biochemistry 19, 3665-3672 https://doi.org/10.1021/bi00557a005

Chapman D., Gomez-Fernandez J. C., Goni F. M. (1979): Intrinsic protein-lipid interactions. Physical biochemical evidence. FEBS Lett. 98, 211-223

https://doi.org/10.1016/0014-5793(79)80186-6

Freeman T. L., Haver A., Duryee M. J., Tuma D. J., Klassen L. W., Hamel F. G., White R. L., Rennard S. I., Thiele G. M. (2005): Aldehydes in cigarette smoke react with the lipid peroxidation product malonaldehyde to form fluorescent protein adducts on lysines. Chem. Res. Toxicol. 18, 817-824 https://doi.org/10.1021/tx0500676

Galor A., Lee D. J. (2011): Effects of smoking on ocular health. Curr. Opin. Ophthalmol. 22, 477-482 https://doi.org/10.1097/ICU.0b013e32834bbe7a

Goodman S. R., Branton D. (1978): Spectrin binding and the control of membrane protein mobility. J. Supramol. Struct. 8, 455-463 https://doi.org/10.1002/jss.400080408

Kewal K. J. (2011): The Handbook of Neuroprotection. Humana Press, Springer

Lin P., Loh A. R., Margolis T. P., Acharya N. R. (2010): Cigarette smoking as a risk factor for uveitis. Ophthalmology 117, 585-590 https://doi.org/10.1016/j.ophtha.2009.08.011

Lin S. Y., Li M. J., Liang R. C., Lee S. M. (1998): Non-destructive analysis of the conformational changes in human lens lipid and protein structures of the immature cataracts associated with glaucoma. Spectrochim. Acta A Mol. Biomol. Spectrosc. 54, 1509-1517
https://doi.org/10.1016/S1386-1425(98)00175-9

Low P. S., Willardson B. M., Mohandas N., Rossi M., Shohet S. (1991): Contribution of the band 3-ankyrin interaction to erythrocyte membrane mechanical stability. Blood 77, 1581-1586

Lux S. E. (1979): Spectrin-actin membrane skeleton of normal and abnormal blood cells. Semin. Hematol. 16, 21-51

Lux S. E., John K. M., Ukena T. E. (1978): Diminished spectrin extraction from ATP depleted human erythrocytes. Evidences relating spectrin to changes in erythrocyte shape and deformability. J. Clin. Invest. 61, 815-827 https://doi.org/10.1172/JCI108996

Mello N. K. (2010): Hormones, nicotine, and cocaine: clinical studies. Horm Behav. 58, 57-71 https://doi.org/10.1016/j.yhbeh.2009.10.003

Padmavathi P., Reddy V. D., Kavitha G., Paramahamsa M., Varadacharyulu N. (2010): Chronic cigarette smoking alters erythrocyte membrane lipid composition and properties in male human volunteers. Nitric Oxide 23, 181-186 https://doi.org/10.1016/j.niox.2010.05.287

Pryor W. A., Stone K. (1993): Oxidants in cigarette smoke: radicals, hydrogen peroxide, peroxynitrate, and peroxynitrite. Ann. NY Acad. Sci. 686, 12-28 https://doi.org/10.1111/j.1749-6632.1993.tb39148.x

Reddy V. D., Padmavathi P., Paramahamsa M., Varadacharyulu N. C. (2009): Modulatory role of Emblica officinalis against alcohol induced biochemical and biophysical changes in rat erythrocyte membranes. Food Chem. Toxicol. 47, 1958-1963 https://doi.org/10.1016/j.fct.2009.05.014

Rose G. D., Glerasch L. M., Smith J. A. (1985): Turns in peptides and proteins. Adv. Protein Chem. 37, 1-109 https://doi.org/10.1016/S0065-3233(08)60063-7

Roesel M., Ruttig A., Schumacher C., Heinz C., Heiligenhaus A. (2011): Smoking complicates the course of noninfectious uveitis. Graefes Arch. Clin. Exp. Ophthalmol. 249, 903-907 https://doi.org/10.1007/s00417-010-1597-1

Satici A., Bitiren M., Ozardali I., Vural H., Kilic A., Guzey M. (2003): The effects of chronic smoking on the ocular surface and tear characteristics: a clinical, histological and biochemical study. Acta Ophthalmol. 81, 583-587 https://doi.org/10.1111/j.1395-3907.2003.00158.x

Schultz C. P., Wolf V., Lange R., Mertens E., Wecke J., Naumann D., Zähringeri U. (1998): Evidence for a new type of outer membrane lipid in oral spirochete Treponema denticola. J. Biol. Chem. 273, 15661-15666 https://doi.org/10.1074/jbc.273.25.15661

Sherif S. M. (2010): The impact of elevated blood glycemic level of patients with type 2 diabetes mellitus on the erythrocyte membrane: FTIR study. Cell Biochem. Biophys. 58, 45-51 https://doi.org/10.1007/s12013-010-9092-1

Sprague R. S., Stephenson A. H., Bowles E. A., Stumpf M. S., Lonigro A. J. (2006): Reduced expression of G(i) in erythrocytes of humans with type 2 diabetes is associated with impairment of both cAMP generation and ATP release. Diabetes 55, 3588-3593 https://doi.org/10.2337/db06-0555

Susi H., Timasheff S. N., Stevens L. (1967): Infrared spectra and protein conformations in aqueous solutions. I. The amide I band in $\mathrm{H} 2 \mathrm{O}$ and D2O solutions. J. Biol. Chem. 242, 5460-5466 
Swapna I., Sathyasaikumar K. V., Murthy C. R., Dutta-Gupta A., Senthilkumaran B. (2006): Changes in cerebral membrane lipid composition and fluidity during thioacetamide-induced hepatic encephalopathy. J. Neurochem. 98, 1899-1907 https://doi.org/10.1111/j.1471-4159.2006.04028.x

Szalontai B., Kóta Z., Nonaka H., Murata N. (2003): Structural consequences of genetically engineered saturation of the fatty acids of phosphatidylglycerol in tobacco thylakoid membranes. An FTIR study. Biochemistry 42, 4292-4299 https://doi.org/10.1021/bi026894c

Thorne J. E., Daniel E., Jabs D. A., Kedhar S. R., Peters G. B., Dunn J. P. (2008): Smoking as a risk factor for cystoids macular edema complicating intermediate uveitis. Am. J. Ophthalmol. 145, 841-846

https://doi.org/10.1016/j.ajo.2007.12.032

Zagorski M. G., Barrow C. J. (1992): NMR studies of amyloid betapeptides: protein assignments, secondary structure, and mechanism of an alpha-helix-beta-sheet conversion for a homologous, 28-residue N-terminal fragment. Biochemistry 31, $5621-5631$

https://doi.org/10.1021/bi00139a028

Received: July 18, 2016

Final version accepted: September 23, 2016

First published online: May 4, 2017 